\title{
Inflation and Growth: Some Theory and Evidence ${ }^{+}$
}

\author{
by \\ Max Gillman*, Mark Harris**, and László Mátyás*** \\ * Central European University, Department of Economics \\ ** Melbourne Institute of Applied Economic and Social Research, the University of Melbourne, and \\ Central European University, Department of Economics. \\ *** Central European University, Department of Economics, and University of Paris XII, Erudite
}

\begin{abstract}
The paper presents a monetary model of endogenous growth and specifies an econometric model consistent with it. The economic model suggests a negative inflation-growth effect, and one that is stronger at lower levels of inflation. Empirical evaluation of the model is based on a large panel of OECD and APEC member countries over the years 1961-1997. The hypothesized negative inflation effect is found comprehensively for the OECD countries to be significant and, as in the theory, to increase marginally as the inflation rate falls. For APEC countries, the results from using instrumental variables also show significant evidence of a similar behavior.
\end{abstract}

JEL: O42, C23, C51, E13

Keywords: Endogenous Growth, Panel Data, Inflation, Non-linearity

\footnotetext{
${ }^{+}$Research assistance by László Konya, Rezida Zakirova, and Anton Nakov and comments by Michal Kejak are kindly acknowledged.
} 


\section{Introduction}

Kormendi and McGuire (1985) helped to shift the conventional empirical wisdom about the effects of inflation on economic growth: from a positive one, as some interpret the Tobin (1965) effect, to a negative one, as Stockman's (1981) cash-inadvance economy with capital, has been interpreted. ${ }^{1}$ They found for a cross-section of 47 countries during the period 1950-1977, a significant negative effect of inflation on growth (although this effect became insignificant when the investment/output ratio was included). Recent panel evidence has strengthened and further qualified the nature of this negative effect. Khan and Senhadji (2000) find a significant negative effect of inflation that starts above a certain "threshold" inflation rate level and continues for all higher rates. The threshold inflation rate is found to be $1 \%$ for industrial countries and $11 \%$ for developing countries; below these rates the inflationgrowth effect is positive. Ghosh and Phillips (1998) find, for IMF member countries, at low inflation rates a positive inflation-growth correlation, and for higher inflation rates a negative inflation-growth relation. Further the negative relation that they find is non-linear whereby the marginal effect is stronger at lower inflation rates than at higher ones; see also Fischer (1993). Judson and Orphanides (1998) find a significant negative inflation-growth effect for a large panel; but when splines are introduced the relation turns out to be insignificant for inflation rates below $10 \%$.

Linking such evidence with a theoretical model has largely escaped the literature. Both the Tobin and Stockman papers actually show theoretically the effect of inflation on output rather than on the balanced-growth rate of output. Sidrauski's (1967) money-in-the-utility function model derives only a transitional effect of inflation on 
the growth rate; Ireland's (1994) AK model, with cash-in-advance and an explicit credit sector, also shows only such a transitional effect, with a zero balanced-growth effect. Chari, Jones and Manuelli (1996) find in calibrations of their model a negative effect of inflation on the balanced-growth rate, but one of a nearly insignificant magnitude. By contrast, Gomme (1993) uses Lucas' (1988) endogenous growth framework combined with a cash-in-advance exchange technology to calibrate a significant negative effect of inflation on growth. However none of these endogenous growth, monetary, papers have used an econometric model to test this relationship.

The contribution of our paper is that, first of all, unlike previous work, the empirical evidence is tightly linked to a theoretical model, as opposed being simply "an empirical finding". In growth theory, ever since the Ramsey-Cass-Koopmans theory endogenized the savings rate of the Solow model, by framing it in a utility optimization framework, the growth rate has depended primarily on one variable: the rate of return to capital. Taxes that decrease that rate of return, the net real interest rate, decrease the growth rate. Models that explain growth endogenously, with a Lucas-Uzawa human capital accumulation, further develop the theory by implying that the growth rate also depends on the rate of return to human capital, whereby the rate of return on all forms of capital must be equal in the balanced-growth equilibrium. A tax on either form of capital induces a lower return in equilibrium on all forms of capital. When such endogenous growth models are set within a monetary exchange framework, of Lucas (1980), Lucas and Stokey (1987), or McCallum and Goodfriend (1987), the inflation tax also will affect the rate of return on capital. In particular, the inflation tax induces goods to leisure substitution that lowers in the first

\footnotetext{
${ }^{1}$ Stockman (1981) finds a negative effect of inflation on output, not on the growth rate of output, but
} 
instance the return to human capital, and so lowers both the return on all capital and the growth rate.

This paper presents a model with this feature of the inflation rate reducing the return to capital. This is then exploited as the basis for a parsimonious empirical theory of growth. Growth is explained through factors that reflect the return to physical and human capital in terms of easily measurable variables. In particular the real interest rate is chosen for the return to physical capital, and this is proxied with the savings rate in a way well-justified by the theory. Any further changes across countries to this real rate, for example as caused by differing tax regimes, are accounted for via use of fixed country specific effects within the econometric model. This is essential as a tax on capital income directly reduces the growth rate, while a tax on labor income causes goods to leisure substitution that lowers the rate of return on human capital and so can also lower the growth rate. The one systematic, easily measured, tax on human capital across countries that our model specifies -- the inflation rate -- is included in the empirical specification as a central variable. It is acknowledged that the theory is concerned with the equilibrium along the balanced growth path, and that it implicitly includes transitional approaches to the balanced growth rate. Following the literature, a variable of the ratio of the output in the US to that of each country is also included in the econometric specification to capture such transitional dynamics; in particular, the growth rate would be expected to be higher the farther below the US level is a country's output level.

this still stands as a work shifting the focus in the other direction. 
Two additional aspects of the empirical work are also linked to the theory. Time effects are conditioned upon (again as fixed parameters in the econometric model), and interpreted as being related to unexpected international changes in the inflation rate. The assumed exogeneity of the inflation rate variable relative to its effect on the growth rate, is also investigated. Since, in the model, the exogenous rate of change of the money supply directly determines the inflation rate, which in turn induces reallocations that lower the growth rate, the money supply growth rate (and its lag) are employed as the instrumental variables for the inflation rate in the estimation procedure. This contrasts with the standard relatively ad hoc specification of the instruments, as for example in Ghosh and Phillips (1998).

No other explanatory variables are included in the econometric model, as no others are derived from the theoretical one. However, the theoretical model also predicts a non-linearity in the inflation-growth effect, whereby the effect is marginally stronger at lower inflation rates than at higher ones. And this negative effect is predicted to start at the Friedman optimum of a zero nominal interest rate, where it is marginally the strongest, and apply to the whole inflation rate range. This theoretically predicted non-linearity is explored using a variety of techniques (natural logarithms, quadratic and spline functions). With the non-linearity formalised, and framed within the theoretic model, a more robustly negative inflation-growth effect is found than in most other works. In particular, the effect is negative and significant at low inflation rate ranges for the $\mathrm{OECD}$, as found with both splines and instrumental variables, and the marginal effect is stronger the lower is the inflation rate. For example, when going from a $0-10 \%$ spline to a $0-5 \%$ spline, for the quadratic specification, the negative coefficient nearly doubles in magnitude and remains highly significant. 
Results here are differentiated between OPEC and APEC regions, with the full sample results reported as well. For the OPEC region, this gives more striking support for the theory, as the results hold for each of our specifications, with and without instruments. For the APEC region, interestingly we find support for a significant, non-linear, negative effect, but only with the instrumental variables approach. And the magnitude of the effect tends to be smaller than in the OECD results. This suggests that in the APEC region, with typically less developed financial markets and with less government central bank independence, the inflation-growth effect emerges but as an endogenous process with less strength. The endogeneity of the inflation process for the APEC region is mteworthy because it may help explain why others have found a positive inflation rate effect at the low inflation rate range. In the APEC sample, for the spline over the $010 \%$ inflation range, the results here show an insignificant but positive inflation growth effect. For a 0-5\% range, the spline becomes significant and positive, in the quadratic specification. However the instrumental variables estimation shows only a negative relation for all positive inflation rates. Thus the positive, APEC, lower spline, results without instrumental variables must be heavily qualified by the possibility of endogeneity bias that is indicated by the reverse finding of a negative effect with instrumental variables.

To summarize: previous work did not provide a theoretical model for testing, nor link the variables of the econometric model systematically to a single internally consistent theory. Nor at the same time did previous work link the empirical non-linearity to such a theory, base the instruments on the same theory, or use such a theory to explain both OPEC and APEC regions. And it is exactly the use of such a theory that leads us 
to find strong support for a negative inflation-growth effect for the OECD sample, the APEC sample, and for the full sample, as well as for all positive inflation rates.

Finally, it should be noted that the model does not dismiss the Tobin effect, but actually re-states it in general equilibrium terms. The endogenous growth, cash-inadvance, setting means that the inflation tax reduces the return on human capital, and that the return on physical capital must adjust downwards in equilibrium. This adjustment requires an increased investment and an increased capital/labour usage across all sectors. This input realignment slightly mitigates the degree to which the return on human capital and physical capital must fall as a result of an increase in the inflation rate. Thus the Tobin effect is the more efficient use of inputs given the higher tax on labour relative to leisure that results from an inflation rate increase. It means a higher physical capital usage relative to labour, and a slightly smaller decline in the balanced-path growth rate. However, the effect of inflation on the balancedgrowth rate is still negative, in contrast to the exogenous growth, exogenous savings rate, monetary model of Tobin. This therefore extends the capitatonly, cash-inadvance, models of Stockman (1981), Ireland (1994), and Dotsey and Sarte (2000), and the exogenous growth monetary models of Ahmed and Rogers (2000), by postulating a model with the existence of a Tobin-type effect even while the end result is a negative effect of inflation on growth.

After presenting the model, Section 2 shows the nature of the inflation-growth effect along the balanced-growth path equilibrium, including its non-linearity and an operative Tobin- type effect. This section and the Appendix also detail how the savings and growth rates are related. Section 3 describes the data and contains some 
preliminary description. The econometric model is specified in Section 4, and robustness and endogeneity checks are introduced in Section 5. The estimation results are presented in Sections 6 and 7, and Section 8 qualifies and concludes.

\section{Endogenous Growth Monetary Framework}

The representative agent works in a constant-returns-to-scale (CRS) goods sector, that employs physical capital and effective labour. Effective labour is defined as raw labour factored by the human capital (quality indexed). The agent also devotes recourses to two additional, implicit price, sectors. These are the CRS human capital production that involves the investment of capital and effective labour, and a credit services sector that involves only effective labour in a diminishing returns technology. The agent faces four constraints on the maximization of utility over goods and leisure in terms of the flow of human capital; the flow of financial capital that is comprised of money and physical capital; the stock of financial capital; and the exchange technology. The technology of the credit services sector is built into the cash-inadvance exchange constraint.

At time $t$, denote the real quantities of goods by $c_{t}$, and the fraction of time spent in leisure, in credit services production, and in goods production by $x_{t}, l_{F t}$, and $l_{G t}$. The share of physical capital in goods production is given by $s_{G t}$. The stocks of physical and human capital and their depreciation rates are given by $k_{t}, h_{t}, \delta_{k}$, and $\delta_{h}$ respectively. Denote the real marginal products of capital and effective labour by $r_{t}$, the real interest rate, and $w_{t}$, the real wage. The positive shift parameters of the production functions of goods, credit services, and human capital are $A_{G}, A_{F}$, and 
$A_{H}$. Nominal variables are the price of goods $P_{t}$, the stock of nominal financial capital $Q_{t}$, the stock of money $M_{t}$, and the lump sum government trans fer of cash $V_{t}$ that is a constant fraction $\sigma$ of the money stock. Parameters of the utility function are $\rho, \theta$, and $\alpha$, and the technology parameters, all in the $(0,1)$ interval, are $\beta, \varepsilon$, and $\gamma$

\subsection{The representative agent problem}

Let the output of goods, denoted by $y_{t}$, be produced by the function

$$
y_{t}=A_{G}\left(s_{G t} k_{t}\right)^{1-\beta}\left(l_{G t} h_{t}\right)^{\beta} .
$$

Let $a_{t} \in(0,1)$ denote the fraction of purchases made with cash, whereby the cash-inadvance constraint is

$$
M_{t}=a P_{t} c_{t}
$$

The money supply progresses through the government transfer, which is assumed to be made at a constant rate $\sigma$ :

$$
M_{t+1}=M_{t}+V_{t}=M_{t}(1+\sigma) \text {. }
$$

The share of purchases made by credit by definition is given by $1-a_{t}$. The credit services for buying the fraction $\left(1-a_{t}\right)$ of goods with credit, instead of cash, are produced through the function

$$
\left(1-a_{t}\right)=A_{F}\left(l_{F t} h_{t} / c_{t}\right)^{\gamma}
$$

The term $l_{F t} h / c_{t}$ is the effective labour time per unit of consumption goods. Equation (4) can be solved for $a_{t}$ and substituted into the cash constraint, Equation (2). This gives an exchange constraint that is actually just a special case of the 
McCallum and Goodfriend (1987) shopping-time economy, as for example in Lucas (2000), except that here we are modeling "banking time". ${ }^{2}$

The nominal financial capital constraint is

$$
Q_{t}=M_{t}+P_{t} k_{t}
$$

The nominal income constraint derives from setting the change in financial capital to zero. This sets income of $r_{t} P_{t} s_{G t} k_{t}+w_{t} P_{t} l_{G t} h_{t}+V_{t}+\dot{P}_{t} k_{t}$ minus expenditure of $P_{t} c_{t}+\delta_{K} P_{t} k_{t}$ equal to zero:

$$
\dot{Q}_{t}=r_{t} P_{t} s_{G t} k_{t}+w_{t} P_{t} l_{G t} h_{t}+V_{t}+\dot{P}_{t} k_{t}-\delta_{K} P_{t} k_{t}-P_{t} c_{t}
$$

Human capital is CRS produced, with capital not used in goods production $\left(1-s_{G t}\right) k_{t}$ and time not used in leisure, credit services production, or goods production $\left(1-x_{t}-l_{G t}-l_{F t}\right)$. The investment in human capital is given by

$$
\dot{h}=A_{H}\left(1-x_{t}-l_{G t}-l_{F t}\right)^{\delta} h_{t}\left(1-s_{G t}\right)^{1-\delta} k_{t} .
$$

The representative agent optimisation problem is presented in the Appendix.

\subsection{The Effect of Inflation on the Balanced-Growth Path}

The model's major trade-off is given by the marginal rate of substitution between goods and leisure. Dropping time notation, this can be written as

$$
\alpha c / x h=w /\left(1+a R+w l_{F} h / c\right),
$$

where $R$ is defined as the nominal interest rate. Equation (8) sets the marginal rate equal to the shadow price of leisure $w$ divided by the shadow price of goods, $1+a R+w l_{F} h / c$. The goods shadow price includes a goods price of 1 and a cost of

\footnotetext{
${ }^{2}$ See Gillman and Kejak (2000b) for a proof of the shopping-time/banking-time equivalence, and for further discussion.
} 
exchange that is the sum of the average cash cost $a R$, and the average credit $\operatorname{cost} w l_{F} h / c$. This relation shows that an increase in the inflation rate, which increases $R$ directly, goes in the direction of causing $c / h$ to fall relative to $x$ by a firstorder effect. There are second-order changes of lesser magnitude that go in the opposite direction. In particular, $a$ falls and $w$ rises as the inflation rate goes up, but calibrations in Gillman and Kejak (2000a) show that the rise in $R$ ends up being dominant for levels of the inflation rate below hyperinflation, as typically defined, and so $c / h$ falls and $x$ rises. $^{3}$

Equilibrium along the balanced-growth path is characterized by a balanced-growth rate $g$ whereby

$$
g \equiv \dot{c} / c=\dot{k} / k=\dot{h} / h=[r-\rho] / \theta,
$$

and by the equality of the return of physical capital in goods production to the return on effective labour in human capital production:

$$
r=(1-x) A_{H} \beta\left(s_{H} k / l_{H} h\right)^{1-\beta} .
$$

Equations (9) and (10) imply that an increase in leisure $x$ has a strong effect on decreasing $r$ and the growth rate. In combination with equation (8), these equations show how inflation can cause a negative growth effect through the induced increase in leisure.

Calibrations show that this negative effect is very robust. It occurs for a wide range of parameters around the baseline, which is set by using standard values from the literature. For the non-standard parameters, mainly $\gamma \in(0,1)$ of the credit production

\footnotetext{
${ }^{3}$ See Gillman and Kejak (2000b) for a human-capital only version of the model, which enables a closed-form solution, and details of how the inflation-growth effect turns positive only for rates of
} 
sector, the full range of values was experimented with and all yield the negative inflation-growth effect. Further, in the case of no physical capital, the existence and uniqueness of the equilibrium can be proved analytically. The one important qualification is that the negative inflation-growth effect occurs only for inflation rates up to a certain very high level, depending on the calibration values. For standard parameters, this upper value is between 100 and $200 \%$, which is effectively above any stationary rate of inflation likely to be experienced in any given country. Generally when such high rates are experienced the country is entering the region of hyperinflation, with unexpectedly accelerating inflation that by nature is not a balanced-growth equilibrium that the model presented here describes.

\subsection{Non-linearity of the Inflation-Growth Effect}

The non-linear nature of the inflation-growth effect is another dimension of the model. When the inflation rate rises above a certain, very high, value, the inflationgrowth effect monotonically falls as the inflation rate rises, until the effect is zero, and then turns positive. Therefore the effect is marginally stronger at a nominal interest rate of zero, and of an increasingly sma 11 magnitude as the inflation rate rises. This gives rise to the prediction of an important non-linearity that will be allowed for in the econometric model.

The intuition for the non-linearity is supplied by the use of the microfounded exchange technology. When the inflation rate is at a low level, the consumer uses mainly money and just a little amount of credit. The theory implies that the interest

elasticity of money demand is very low in absolute value, or "inelastic", at low

inflation above the level at which the magnitude of the int erest elasticity equals one. 
inflation rates, and that it becomes increasingly more elastic (more negative) as the inflation rate rises. ${ }^{4}$ With an inelastic money demand, the agent substitutes from goods to leisure, and a bit from money to credit when the inflation rate goes up. As the interest elasticity increases with increases in the inflation rate, the agent still substitutes from goods to leisure but increasingly substitutes towards the use of credit away from money. The rising interest elasticity, and the emergence of increasing substitution towards credit as the primary substitution channel, means that the agent relies less on the goods to leisure channel. Therefore leisure increases at a decreasing rate, and the growth rate falls by increasingly smaller amounts. The bigger increases in credit and the smaller increases in leisure, as the inflation rate rises, explains why the inflation-growth effect is predicted to be of smaller magnitude at higher inflation rates.

\subsection{Tobin Effect and the Savings Rate}

The Tobin effect here is a general equilibrium one along the balanced growth path whereby an increase in the inflation rate causes an increase in the input price ratio, $w / r$, and in the capital to effective labour ratio in both goods and human capital production. Calibrations show that the inflation rate robustly causes a decrease in the return to capital, $r$, as the return on human capital is forced down, and an increase in the real wage $w$, as a result mainly of the consumer using more leisure. This induces substitution from effective labour to capital, and produces the model's Tobin-type increase in capital intensity, even while causing a decrease in the growth rate.

\footnotetext{
${ }^{4}$ See relatedly Mulligan and Sala-i-Martin (2000).
} 
The savings rate can also be shown to depend on the input price ratio, $w / r$, on leisure, and on the nominal interest rate (see the Appendix for details). The effect of an increase in the real interest rate $r$ is to increase the savings rate. It is on this basis that we proxy the effect of the real interest rate on the growth rate through the use of the savings rate. This abstracts from other effects on the savings rate such as the real wage, and so makes the savings rate an imperfect proxy of the real interest rate.

\section{The Data and Preliminary Analysis}

Three panels of countries are examined. The first consists of 29 OECD countries: Australia, Austria, Belgium, Canada, Czech Rep., Denmark, Finland, France, Germany (unified), Greece, Hungary, Iceland, Ireland, Italy, Japan, Korea Rep., Luxembourg, Mexico, the Netherlands, New Zealand, Norway, Poland, Portugal, Spain, Sweden, Switzerland, Turkey, the United Kingdom and the USA. The second panel consists of 18 APEC members (six of them jointly belonging to the OECD): Australia, Canada, Chile, China, Hong Kong, Indonesia, Japan, Malaysia, Mexico, New Zealand, Papua New Guinea, Peru, Philippines, Russia, Singapore, Thailand, Vietnam and the USA. Finally, the third panel includes all 41 countries.

The data are from EconData and World Bank World Tables. The data set comprises annual measures on the following variables:

PCGDP: $\quad$ Per capita GDP, 1995 \$US million;

GDPGR: Average annual growth rate of real GDP, \%pa;

GDPDEF: GDP deflator, \%pa inflation rate; and

INVPGDP: Proportion of gross domestic investment in GDP, $\%$. 
The original sample period is 1961-1997 for all countries, except the Czech Republic (1985-1997), Germany (1992-1997), Turkey (1969-1997), Poland (1985-1997), Russia (1990-1997) and Vietnam (1986-1997). ${ }^{5}$

To avoid data that is part of a hyperinflation period, the data alternatively is capped at an inflation rate of 50,100, and $150 \%$, whereby values with higher rates are dropped from the sample.

There appears to be no one definitive measure of the "inflation rate" in the literature. For example, Barro (1995) uses the "simple" inflation rate, $\pi$; Judson and Orphanides (1996) use $\log (1+\pi)$; Ghosh and Phillips (1998) use four measures $-\pi ; \pi /(1+\pi)$, $\log (1+\pi)$ and a non-monotonic transformation, $(1 /(1-\gamma)) \pi^{(1-\gamma)} ;$ Khan and Senhadji (2000) use the $\log (\pi)$. These alternative measures have different implications for inference and the marginal effect (and elasticity) of $\pi$ on (with respect to) growth.

An issue with the natural logarithm transformation is that it is not defined for $\pi<0$. However, the loss of observations can be negated somewhat by the $\log (1+\pi)$ favored by some authors. Moreover, in the data set used in this study, there is also the problem of hyperinflation rates, for which the economic model is not designed(in the raw data, inflation rates range from $-11 \%$ to over $6,000 \%)$. To reduce the chances of such large outliers unduly affecting results, the inflation rates are constrained initially

\footnotetext{
${ }^{5}$ When the money supply is used as an instrument, this further reduces the sample size due to more missing values.
} 
at the top end to be below $150 \%{ }^{6}$ The distribution of these rates is plotted in Figure 1 below.

\section{Figure 1: Distribution of Inflation Rates}

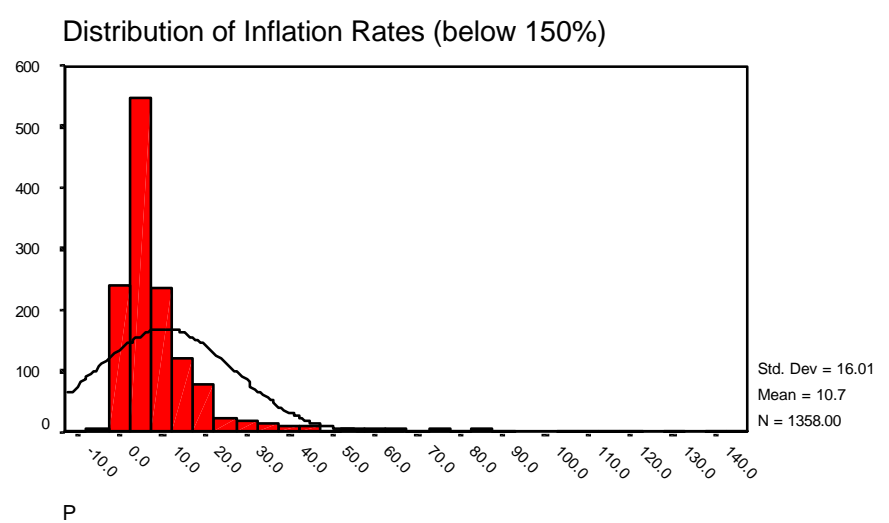

It is apparent that substantial outliers are still heavily skewing the distribution of inflation rates, such that there remains the possibility that these will unduly bias the estimated inflation effect. Conversely, the use of $\log (1+\pi)$, visibly results in a much more normally distributed range of inflation rates (Figure 2)

\footnotetext{
${ }^{6}$ Sensitivity analysis on this hyper-inflation cut-off point is also undertaken.
} 
Figure 2: Distribution of $\log (1+\pi)$

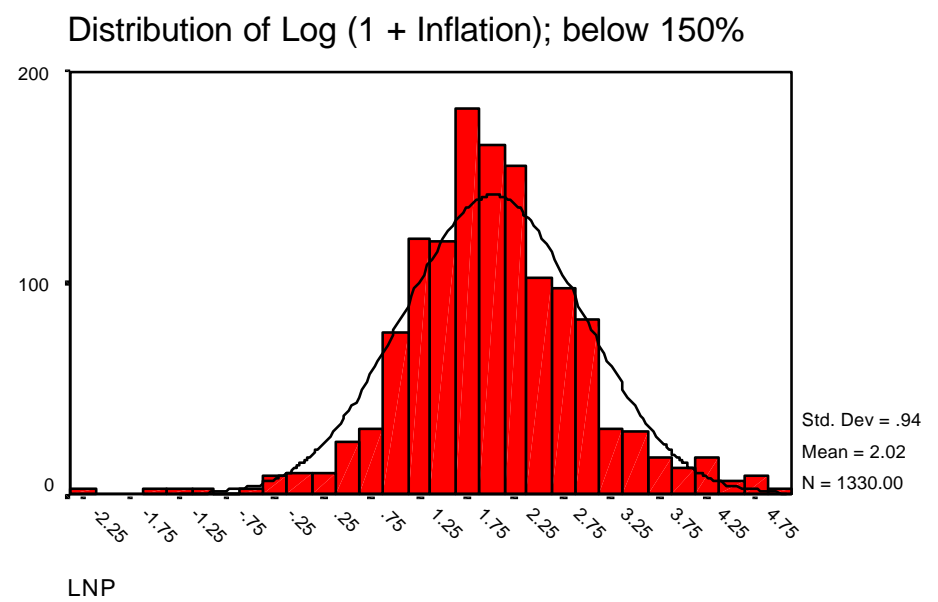

The sample correlation between $\pi$ and GDP growth is given in Table 1, suggesting a significantly strong negative (and linear) relationship between growth and inflation.

\section{Table 1: Sample Correlation of Inflation and Growth}

\begin{tabular}{|l|l|}
\hline Pearson Correlation & $-0.135^{* *}$ \\
Significance. (2-tailed) & .000 \\
$\mathrm{~N}$ & 1,358 \\
\hline \multirow{2}{*}{ Correlation is significant at the 0.01 level (2-tailed). }
\end{tabular}

Obviously such correlation is simply a measure of linear association, and tells us nothing about any non-linear effect. In Figure 3 the mean growth rate is plotted for various inflation bands. Again, there does appear to be a negative inflation rate effect, and moreover one which is non-linear and that becomes more pronounced at inflation rates of over $5 \%$. 
Figure 3: Average Growth Rates for Inflation Bands

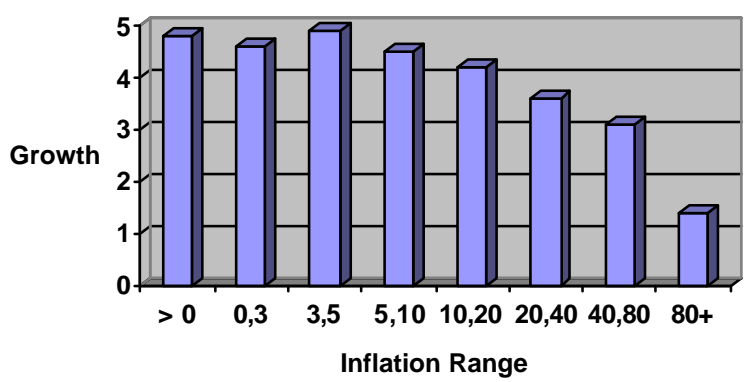

Figures 4 and 5 plot the joint distribution of inflation and growth rates for the full sample, and for OECD countries only, respectively. The rates of inflation are banded as per Figure 3.

Figure 4: Joint Distribution of Inflation $(<150 \%)$ and Growth Rates; OECD

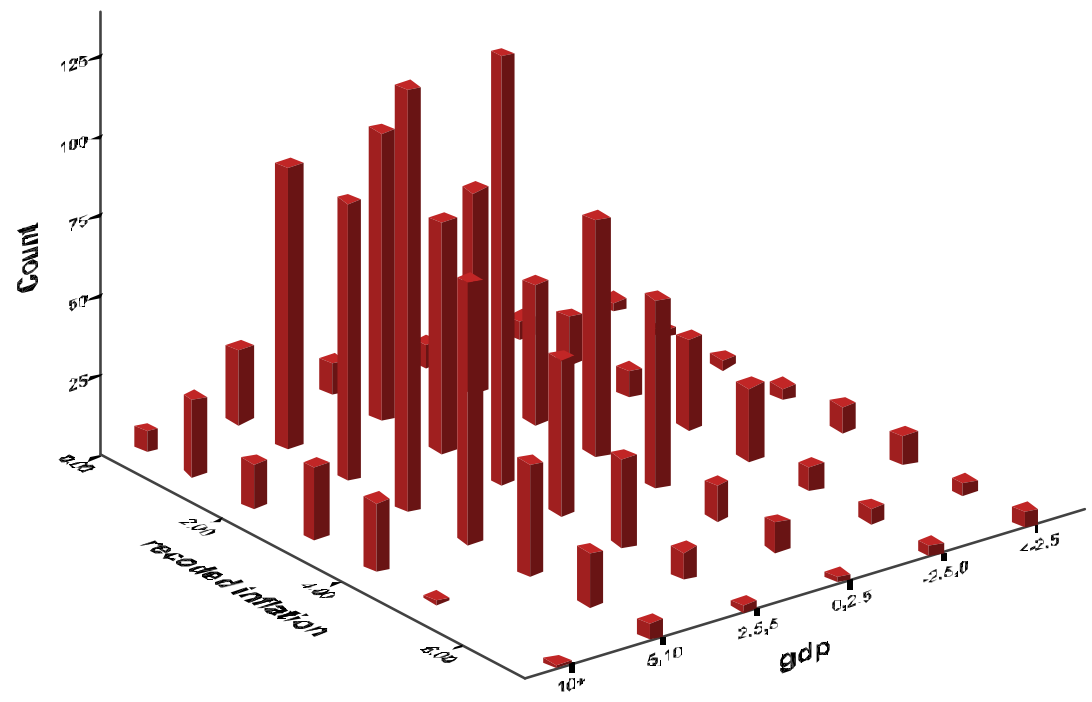


Figure 5: Joint Distribution of Inflation $(<150 \%)$ and Growth Rates; OECD

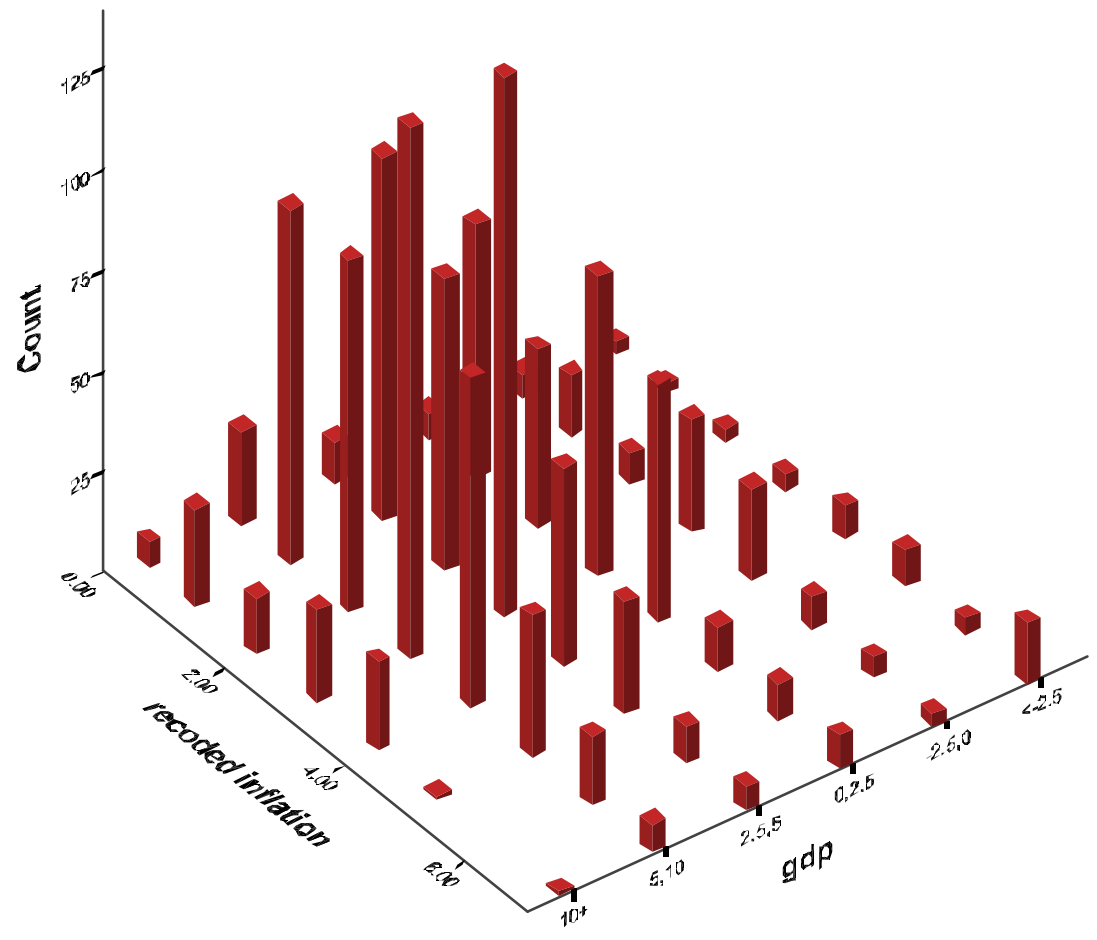

Both of these figures suggest a "stacking-up" of growth rates against the inflation rates (apart from negative inflation rates), as the model suggests, an effect that appears to be more pronounced in the OECD sample.

Although such simple correlation and data analysis suggest a strong, non-linear, negative inflation effect, it is, of course, important to also simultaneously condition on 
the other drivers of economic growth, as suggested by the model exposition presented in Section 2.

\section{The Econometric Model}

The economic model derived in Section 2, leads to the following econometric specification

$$
y_{i t}=\alpha_{i}+\lambda_{t}+\beta_{g} g\left(\pi_{i t}\right)+\beta_{I / y} \ln \left(I_{i t} / y_{i t}\right)+\beta_{y / y} \ln \left(y_{U S A t} / y_{i t}\right)+u_{i t}
$$

where: $y_{i t}$ is the average annual growth rate (\% pa) in GDP at constant prices, of country $i$ in year $t$; $\underline{\mathrm{b}}$ the vector of unknown coefficients; $g\left(\pi_{i t}\right)$ a non-linear function of the annual rate of inflation; $I_{i t} / y_{i t}$ the proportion of gross domestic investment in GDP (equal to the savings rate in the representative agent framework); $y_{U S A, t} / y_{i, t}$ the ratio of US output to country $i$ output; $\alpha_{i}$ the country specific, time invariant, effect which captures unobserved country heterogeneity, such as physical tax rates (conditioning on such, allows long-run growth rates to differ across countries, irrespective of their observed heterogeneity); $\lambda_{t}$ the country invariant time effects, which account for any trend-deviation effects; and $u_{i t}$ the usual disturbance term. Signs on the investment/saving rate and on the ratio of incomes are predicted to be positive, while the inflation effect is predicted to be negative.

Several variants of the non-linear relationship between $\pi$ and growth, $g\left(\pi_{i t}\right)$, were experimented with. Following Barro (1995) simply the inflation rate $\pi$, is used. Here $g\left(\pi_{i t}\right)=\sum_{j=1}^{3} D_{j} \beta_{j} \pi_{i t}$, where $D_{j}$ are three dummy variables, where $D_{1}$ represents "low", $D_{2}$ "medium," and $D_{3}$ "high" inflation. That is, the relationship between inflation 
and growth, is allowed to follow a "spline" (or piecewise") function in the level of the inflation rate (restrictions are imposed on the parameters to ensure that the spline function is continuous at the spline knots). Then, following, amongst others Judson and Orphanides (1996), Ghosh and Phillips (1998) and Khan and Senhadji (2000), the relation is $g\left(\pi_{i t}\right)=\log \left(1+\pi_{i t}\right)$. In a similar vein to Judson and Orphanides (1996), this relationship is also allowed to follow a spline function, that is $g\left(\pi_{i t}\right)=\sum_{j=1}^{3} D_{j} \beta_{j} \log \left(1+\pi_{i t}\right)$, and where again the spline knots are tied (which does not appear to be the case with Judson and Orphanides, 1996). In other words, the relationship is allowed to follow a spline function in $\log \left(1+\pi_{i t}\right)$. This specification effectively allows the elasticity to vary across inflation levels. Finally, Barro (1995), is expanded on, by including a squared term of $\pi$, such that $g\left(\pi_{i t}\right)=\sum_{j=1}^{2} \beta_{j} \pi_{i t}^{j}$, that is, $g\left(\pi_{i t}\right)$ is a quadratic in the level (as opposed to the logarithm) of inflation.

From an econometric viewpoint, the country and time effects, can be treated as random variables, leading to a random effects approach, or as fixed parameters, a fixed effects approach (Mundlak, 1978, Hsiao, 1985 and 1986 and Mátyás and Sevestre, 1996). The question of which approach to take, is often dependent upon the extent of expected correlation between the observed and unobserved heterogeneity terms, and whether the effects are of significance in their own right. In such a derived model of growth, it is suspected that there might indeed be correlations between the unobserved effects and the included variables, subsequently biasing any random effects results. Moreover, it is also of interest to see which countries have an innately higher/smaller growth rate, and to highlight any trend-deviation (time) effects. For 
these reasons, a fixed effects approach for both $\alpha_{i}$ and $\lambda_{t}$ was taken. The parameters can be equivalently estimated using dummy variables or the socalled Within estimator (Mátyás and Sevestre, 1996, for example).

\section{Robustness and Endogeneity}

Following the literature several robustness checks were undertaken as far as the specification is concerned, and a focus was given to the extent of endogeneity bias likely to arise from a possible simultaneity of growth and inflation.

In terms of the robustness of the conditioning variables, several authors experiment with different conditioning sets. That is, in addition to inflation, different sets of explanatory variables are included in the econometric specification (for example human capital variables). These different conditioning sets tend to be specified in an ad hoc fashion, and to be insignificant in terms of their effect on the inflation-growth relationship (see, for example, Khan and Senhadji, 2000). Therefore such additional variables were not included. Moreover, the fixed effects employed in the estimation are designed to capture any unobserved (or excluded) time invariant country heterogeneity.

Specific robustness checks are undertaken to the extent that the sample is truncated according to different notions of "hyper-inflation". In the base specifications, such inflation is taken as being anything over 50\%, although truncation points of $100 \%$ and $150 \%$ were also considered. 
The results are tested for any endogeneity bias by considering that the inclusion of the inflation rate assumes that it is an exogenous variable to the growth process. To account for this assumption, the model is re-estimated by the use of Instrumental Variables (IVs). The instruments are current and lagged values of the money supply. ${ }^{7}$ The money supply is chosen as an appropriate instrument since in all standard monetary general equilibrium models the money supply is assumed to be exogenous and, more importantly, this is what actually causes inflation in the economic model. This contrasts to Gosh and Phillips (1998) and Khan and Senhadji (2000), for example, who experiment with differing instrument sets on an ad hoc basis. Moreover, when different instruments sets were experimented with, the results were sensitive to these, presumably as these additional instruments were either not strictly exogenous themselves, and/or were unrelated to the inflation rate.

\section{General Results, Diagnostics and Robustness}

In this section the focus is on the overall model specification. The inflation-growth effect is dealt with in the following Section. All of the results reported in Tables 2 and 3 are from the case when data observations are dropped from the sample if the inflation rates are above $50 \%$. The first of these tables contains the results for the case when the inflation rate is entered in the form, $\ln \left(1+\pi_{i t}\right)$; the IV version of this specification; and finally a spline approximation of a non-linear relationship in this logarithm function. As noted, the latter specification effectively allows elasticities to vary across different inflation levels. The second table contains the results for the level of inflation entered as a quadratic function; the IV version of this specification;

\footnotetext{
${ }^{7}$ As there were more missing values in these series, the IV versions generally have smaller sample size.
} 
and a spline approximation of this non-linear relationship in the level of the inflation rate. Robust standard errors are reported in each case.

The coefficients of each of the investment/savings rate and output ratio variables appear to $æ$ consistent in terms of both parameter estimates and significance levels across both the different estimation methods and different samples. An exception to this is the ratio of US output to individual country output, with IV estimation. This may result from the fact that the sample changes significantly with respect to this particular variable when the sample is reduced to account for missing values of the money supply variable.

In all specifications one rejects the null hypothesis that the individual and time effects are jointly zero. That is, in every specification there is unobserved heterogeneity in growth rates both over time and across countries. As a consequence studies that do not condition on such unobserved heterogeneity will be misspecified and lead to potentially erroneous inference. Moreover, all samples and specifications have approximately the same explanatory power, at just under $50 \%$.

Similarly, in every specification, the use of the Hausman test implies a rejection of the hypothesis that the inflation rate is exogenous. In contrast to this result however, when this endogeneity is accounted for, it appears to have little effect on the inflationgrowth relationship, as illustrated below. The results are also little affected by changes in the definition of hyper-inflation. ${ }^{8}$ Results do vary, as expected, in terms of

\footnotetext{
${ }^{8}$ The results from varying the cut - off rate by which hyperinflation is defined are not presented here but are available on request.
} 
the inflation-growth relationship, according to the countries considered in the sample, as detailed below.

\section{The Inflation-Growth Effect}

The direction and shape of the inflation effect in Tables 2 and 3 is clear for Specifications A and B. A negative effect on the variable $\log (1+\pi)$ implies a nonlinear negative relationship. Similarly, a negative sign on $\pi$ and a positive one on $\pi^{2}$ implies a U-shaped rela tionship. However, due to the construction of the spline terms in Specification $\mathrm{C}$, the implied relationship is not necessarily obvious from the estimated coefficients. Due to this, and also because of the fact that marginal effects and elasticities are not strictly comparable between the log and levels versions of the model, the results of Table 2 and 3 are most easily digested in terms of their implied inflation-growth relationships. The various implied marginal effects are accordingly plotted in Figures 5 to 10 (with all other variables evaluated at appropriate sample means). For both logarithmic and quadratic models, the "growth" labels in the figures refer to Specification A in the results tables, "IVs" to Specification B and "Spline" to Specification C.

For the OECD group of countries, a striking amount of consensus of the non-linear negative inflation effect is witnessed, irrespective of the estimation technique and the specification of the inflation effect in the estimated equation. Figures 5 and 6 clearly show that the marginal negative effect of inflation on growth is greatest at low levels of inflation - in particular at levels below around 10\%. Moreover, all of these separate inflation effects are individually significant, at least at the $10 \%$ level (the one exception is the top section of the spline function in the logarithm specification). And 
the Instrumental Variables estimation gives an almost identical result to the those without instruments, suggesting little effect on the inflation rate coefficient of any endogeneity between inflation and growth.

These results are consistent with Khan and Sedhaji's (2000) findings. They find a positive effect of inflation for OECD countries for rates of inflation up to about $1 \%$. For higher inflation rates, they find a negative non-linear effect, as is found here. Our 0 to $10 \%$ grouping for the low inflation rate shows results of a negative effect. Our results also find a highly significant negative effect for low inflation rates when alternatively using a 0 to $5 \%$ grouping of the low inflation rate range.

When only APEC countries are considered, further reductions in significance levels are witnessed, and the expected non-linear relationship is only somewhat evident in the logarithm specification. However, the estimated standard errors on the spline and quadratic terms in the levels specification for the APEC countries suggest that the non-IV specifications are not appropriate, making the non-IV results suspect.

Figure 10, for example, suggests a positive effect at low levels of inflation, becoming increasingly negative at levels of inflation in excess of around $10 \%$. However, these non-linear specifications do not appear to be particularly appropriate, as only the inflation squared term is ever significant, and even that only weakly so (Table 3). Using the logarithmic form for $g\left(\pi_{i t}\right)$, with respect to the standard Within estimation and that of the spline function, suggests either again a small positive effect at low inflation leveb or a weakly negative non-linear one. However, in neither of these specifications are the inflation variables significant. On the other hand, when IVs are 
used - that is, when one correctly takes into account the endogeneity bias - the inflation rate variable becomes significant, and moreover implies the expected nonlinear negative relationship between inflation and growth.

When the full sample of countries is considered (OECD plus APEC), the general significance level of these inflation variables is lower. The OECD results show up in the entire sample, but with less robustness. The inflation rate coefficients are of less magnitude and have less significance, although all results are generally significant for all the inflation rate ranges. The non-linearity still emerges, although it is more pronounced in the logarithm specification. These results show the importance of separating out the OECD from the APEC countries, in the sense that the negative effect of the inflation rate is more robust and stronger in the separate OECD sample. However, the IV estimation shows, somewhat surprisingly, that the theoretically predicted effect still is operative in the generally less financially-developed APEC group.

\section{Conclusion}

Much has been written about the relationship between inflation and growth, with conflicting empirical results. A candidate explanation for such differences can be categorized into to three reasons. First, the econometric specifications have often neglected the very important cross-country unobserved heterogeneity, and also have lacked time effects that account for trend-deviations. Second, the non-linearity and parsimonious specification arising out of a single, comprehensive, theoretical growth model has not been taken into account. This paper presents an endogenous growth model that implies both a significant, negative, non-linear inflation effect and an 
appropriate econometric specification. Third, the instruments to account for a possible endogeneity of the inflation rate typically have not been theoretically derived from the same self-contained model. This has resulted in the use of weak instruments, with all of their associated well-known problems. The use of the money supply as the instrument is a theoretically-given choice and it results in a significant, non-linear, inflation-growth effect in both OECD and APEC samples.

The estimation results based on a panel of OECD and APEC countries show that the reduction of high and medium inflation to moderate single digit figures has a significant positive effect on growth for the OECD countries, and to a lesser extent for the APEC countries as well. It is also clear that the marginal benefit of the deceleration process increases as the inflation rate is lowered. Further, both unobserved time and country effects prove to be important. While country effects could in part capture differences in tax regimes, a possible economic interpretation of the time effects is that they represent unexpected inflation.

In qualification, the results do not indicate mutatis mutandi that when inflation falls there will be a significant negative growth effect. It could be that external shocks that induce a general economic downturn can dominate the model's explanatory variables, including the expected inflation effect. In other words, the benign effect of an expected deceleration of inflation may only be observed when the world economy is not facing a sudden growth rate deceleration due to shocks. If the world economy is not facing such external shocks, a reduction in the inflation rate seemingly can produce a considerably higher growth rate. And such an effect might even be stronger 
if the inflation rate should be lowered at the same time as are marginal taxes on capital and labor income.

The theory tested here is based on capturing effects on the return to capital: the savings rate being used to proxy the real return to physical capital, and the inflation tax being used to capture the impact of a major "tax" on human capital. A Lucas (1988)-type endogenous growth monetary model allows for both of these effects to appear with a significant magnitude. It would be challenging to try to disentangle from the inflation effect on growth rates those effects attributable to changes in capital and labor tax regimes. Besides adding capital and labor taxes theoretically, and investigating these effects empirically, the model might also be made stochastic in order to ascertain how inflation variability enters the inflation-growth relation. Judson and Orphanides (1998) find that such variability contributes significantly to the finding of a negative inflation-growth effect, and conjecture that it may be even more important than level effects.

Future work could also involve making the model estimation dynamic in order to examine several issues. The economic model employed here is one of endogenous growth but with no externalities and with behavior very similar to the Solow model except that technological change is explained by human capital accumulation. It was this approach that Schultz (1964) and Lucas (1988) thought might explain why physical/financial capital does not quickly flow to low income countries: because they did not have the human capital to support the inflow. The Lucas model predicts an equilibrium physical capital to human capital ratio that is maintained on the balanced growth path whereby non-stationary variables grow at the same rate, but differences 
in levels of income will persist. Thus Solow-type convergence of the growth rates is predicted within such an endogenous growth setting and can be investigated, with the advantage that the inflation-growth effect appears in the endogenous growth setting. A dynamic estimation approach within the monetary framework would allow simultaneous investigation of the possibility of Phillips curve type effects of unexpected inflation (see Ireland, 1999) even while in the long run the effect is a negative growth effect. However most likely this would require a quarterly data panel rather than the annual one used here, so that unexpected inflation rate changes might be captured. 


\section{REFERENCES}

Ahmed S., and J.H.Rogers, 2000, "Inflation and the Great Ratios: Long term evidence from the US," Journal of Monetary Economics, 45 (1) February: 3-36.

Barro, Robert J., (1995) “Inflation and economic Growth” NBER Working Paper 5326.

Chari, V.V., Larry E. Jones, and Rodolfo E. Manuelli, 1996, "Inflation, Growth, and Financial Intermediation”, Review, Federal Reserve Bank of St. Louis, May/June.

Dotsey, Michael, and Sar te, Pierre-Daniel G., 2000, "Inflation Uncertainty and Growth in a Cash-in-Advance Economy", Journal of Monetary Economics, June, 45(3): 631-55.

Fischer, Stanley, 1993, "The Role of Macroeconomic Factors in Growth," Journal of Monetary Economics, 1993, 32, 485-512.

Ghosh, Atish, and Steven Phillips, 1998, "Inflation, Disinflation, and Growth,” IMF Working Paper, May.

Gillman, Max, and Michal Kejak, 2000a, "Modeling the Inflation-Growth Effect", Central European University Department of Economics Working Paper 7/2000; revised.

Gillman, Max, and Michal Kejak, 2000b, "A Non-linearity in the Inflation-Growth Effect", Central European University Department of Economics Working Paper 14/2000; revised.

Gillman, Max, and Anton Nakov, 2001, "A Revised Tobin Effect from Inflation: Relative Input Price and Capital Ratio Realignments, US and UK, 1959-1999," Central European University Department of Economics Working Paper, WP4/2001.

Gomme, Paul, "Money and Growth: Revisited," Journal of Monetary Economics, 1993, 32, 51-77.

Hsiao, C. (1985); Benefits and Limitations of Using Panel Data, Econometric Reviews, Vol. 4, pp. 121-174.

Hsiao, C. (1986); Analysis of Panel Data, Cambridge University Press, Cambridge.

Ireland, Peter N., 1994, "Money and Growth: An Alternative Approach", American Economic Review, 84(1): 559-571.

Ireland, Peter N., 1999, "Does the time-consistency problem explain the behavior of inflation in the United States?", Journal of Monetary Economics, Vol. 44, No.2 (Special Issue: The Return of the Phillips Curve), pp 259-292.

Jones, L.E., R.E. Maneulli, and H.E. Siu, 2000, “Growth and Business Cycles", NBER Working Paper 7633, April. 
Judson, Ruth, and Orphanides, Athanasios, 1996, "Inflation, Volatility and Growth" Board of Governors of the Federal Reserve System, Finance and Economics Discussion Series, 96/19

Khan, Mohsin S., and Abdelhak S. Senhadji, 2000, "Threshold Effects in the Relationship Between Inflation and Growth”, IMF Working Paper, June.

Kormendi, Roger C., and Meguire, Philip G., 1985, "Macroeconomic Determinants of Growth: Cross-Country Evidence", Journal of Monetary Economics, 16(2): 141-63.

Lucas, Robert E., Jr., 1980, "Equilibrium in a Pure Currency Economy”, Economic Inquiry, 18: 203-222.

Lucas, Robert E., Jr., 1988, "On the mechanics of economic development", Journal of Monetary Economics, 22 (July):3-42.

Lucas, Robert E., Jr., 2000, "Inflation and Welfare", Econometrica, March, Vol. 68 Issue 2, pp. 247-275.

Lucas, Robert E., Jr. and Nancy L. Stokey, 1987, "Money and Interest in a Cash-inAdvance Economy", Econometrica, 55: 491-513.

Mátyás, L. and Sevestre, P., (eds.) (1996), The Econometrics of Panel Data, Kluwer Academic Publishers, the Netherlands.

McCallum, Bennett T., and Marvin S. Goodfriend, 1987, "Demand for Money: Theoretical Studies", in New Palgrave Money, J. Eatwell, M.Millgate and P.Newman, eds., Macmillan Press, New York.

Mulligan, Casey B.; X. Sala-i-Martin, 2000, "Extensive Margins and the Demand for Money at Low Interest Rates," Journal of Political Economy, October, 108(5):961-91.

Mundlak, Y. (1978a); On the Pooling of Time Series and Cross Section Data, Econometrica, Vol. 46, pp. 69-85.

Schultz, Theodore W., 1964, Transforming Traditional Agriculture, University of Chicago Press, Chicago.

Sidrauski, Miguel, 1967, "Inflation and Economic Growth", Journal of Political Economy, 75: 796-810.

Stockman, Alan C., 1981, "Anticipated Inflation and the Capital Stock in a Cash-inAdvance Economy", Journal of Monetary Economics, November, 8(3): 387-93.

Tobin, J., 1965, "Money and Economic Growth", Econometrica, 33, No.4, part 2 (October): 671-684. 


\section{APPENDIX. Representative Agent Equilibrium: Tobin-Effect and Savings Rate}

The agent maximization problem with respect to $c_{t}, x_{t}, s_{G t}, l_{G \tau}, s_{F t}, l_{F t}, M_{t}, Q_{t}, k_{t}$, and $h_{t}$, is

$$
\begin{aligned}
& M a x \sim \mathrm{H}=e^{-\rho t} c_{t}^{1-\theta} x_{t}^{\alpha(1-\theta)} /(1-\theta) \\
& +\phi_{t}\left(M_{t}-\left[1-A_{F}\left(l_{F t} h_{t} / c_{t}\right)^{\gamma}\right] P_{t} c_{t}\right) \\
& +\varphi_{t}\left(Q_{t}-M_{t}-P_{t} k_{t}\right) \\
& +\lambda_{t}\left[r_{t} P_{t} s_{G t} k_{t}+w_{t} P_{t} l_{G t} h_{t}-P_{t} c_{t}+V_{t}-\delta_{k} P_{t} k_{t}+\dot{P}_{t} k_{t}\right] \\
& +\mu_{t}\left[A_{H}\left(\left[1-s_{G t}\right] k_{t}\right)^{1-\delta}\left(\left[1-x_{t}-l_{F t}-l_{G t}\right] h_{t}\right)^{\delta}-\delta_{h} h_{t}\right] .
\end{aligned}
$$

Given constant-returns-to-scale production of goods, with $\beta$ being the Cobb-Douglas coefficient equal to the share of physical capital in output, the ratios of effective physical capital to effective hbor across sectors depend on the input price ratio of the real wage to the real interest rate, as given in

$$
w / r=\left(s_{G} k / l_{G} h\right)(\beta /[1-\beta])=\left(s_{H} k / l_{H} h\right)(\delta /[1-\delta]) .
$$

At the same time that the inflation rate increase causes a lower real interest rate in equation (10), it also causes a higher real wage because of the time that gets used up in credit activity and leisure, instead of being used in goods production, according to calibrations in Gillman and Kejak (2000a). This causes, in equation (12), a rise in $w / r$ and in the effective capital to labor ratios across both the goods and human capital sectors. This factor realignment towards physical capital and away from effective labor is the Tobin effect. The factor realignment slightly decreases the negative growth rate impact of the rise in leisure, but the leisure increase dominates and forces down both the return to human capital and to physical capital, and the growth rate falls. $^{9}$

\footnotetext{
${ }^{9}$ Gillman and Nakov (2001) find cointegration evidence in support of the co-movement of the input price ratio and the capital to effective labour ratios, for post-war US and UK quarterly time series data.
} 
Note that the growth rate falls at a decreasing rate, as the inflation rate increases. This results because leisure usage rises at a decreasing rate. The decreasing rate of leisure use, as the inflation rate rises, is reflected in a rising magnitude of the interest elasticity of money demand. This higher elasticity means the agent shifts more from cash to credit in the purchase of the consumption basket of goods, and engages in less substitution from goods to leisure, causing the growth rate to fall by increasingly less as the inflation rate rises. The non-linearity also applies to the whole equilibrium set of effects that result from increasing the inflation rate. In particular, calibrations confirm that the input price ratio $w / r$ and the capital intensities across sectors also rise at a decreasing rate as inflation goes up. Further this in itself causes an increase in the savings rate, at a decreasing rate.

\section{Growth and the Savings Rate}

In equilibrium the model implies that the growth rate and the savings rate are linked through the real interest rate. Traditional Solow-type exogenous growth models imply that a shift up in the savings rate will cause a higher capital to effective labor ratio and transitionally higher growth. In the model here, the growth rate and savings rate are not directly linked but both depend positively on the magnitude of the real interest rate $r$. To see this more formally, consider the resource constraint, $y=c+i$, that is implicit in equation (6). Also, consider that in the CRS production function of goods, $\quad r=(1-\beta) y / k . \quad$ These facts imply that $s \equiv i / y=1-c / y=1-(c / k)(k / y)=1-([1-\beta] / r)(c / h)(h / k)$. Now consider the model in the case without credit services (cash-only, $a=1$ ). Gomme (1993) finds in a similar model to this case that, with equal depreciation rates for human and for 
physical capital, that $h / k$ is constant as inflation changes (see also Jones, Manuelli, and Siu, 2000, for details about a constant $h / k$ in a non-monetary endogenous growth economy). And $c / h$ from equation (8) in the cash-only case reduces to $c / h=w x /(1+R)$. With $h / k=1$, the savings rate can then be written in this illustrative case as

$$
s=1-[(1-\beta) / r][w x /(1+R)]=1-[w / r][(1-\beta) x /(1+R)]
$$

Equation (13) shows first that the marginal product of capital $r$, as it enters the real wage to real interest rate ratio, is a primary factor positively affecting the savings rate, just as affects the growth rate directly in Equation (9). Leisure $x$ is also in general affected by $r$, but as a lower order effect. And $r$ enters the nominal interest rate $R$ directly by the Fisher equation of interest rates, that holds in this model; through this term an increase in $r$ also causes a direct positive effect on the savings rate. Therefore, inclusion of the savings rate in a relation meant to explain the growth rate is a way to capture the effect of $r$ on both. An extension of the empirical model might also include the marginal product of labor, the real wage $w$ on homogenous labor.

Thus the savings rate goes up because of inflation, through the Tobin effect. But this type of increase in the savings rate is associated with a decrease in the growth rate. When the $r$ rises because of an increase in marginal productivity not induced by an inflation-tax increase, the savings rate rises. By including both the inflation rate and the savings rate in the econometric model, these effects are accounted for separately to some extent, and may be part of the reason why strong, positive, empirical results are found for both the effect of the inflation rate and the savings rate on growth. 
Table 2: Logarithm of Inflation, Logarithm of Inflation - IVs and Spline Function in the Logarithm of Inflation ${ }^{\#}$

\begin{tabular}{|c|c|c|c|c|c|c|}
\hline & \multicolumn{2}{|c|}{$\begin{array}{l}\text { OECD } \\
\text { Coefficient }\end{array}$} & \multicolumn{2}{|c|}{$\begin{array}{l}\text { FULL } \\
\text { Coefficient }\end{array}$} & \multicolumn{2}{|c|}{$\begin{array}{l}\text { APEC } \\
\text { Coefficient } \\
\end{array}$} \\
\hline \multicolumn{7}{|c|}{ Specification A: Within Estimation; $g\left(\pi_{i t}\right)=\ln \left(1+\pi_{i t}\right)$} \\
\hline $\ln \left(I_{i t} / y_{i t}\right)$ & 0.260 & $(0.026)^{*}$ & 0.220 & $(0.020)^{*}$ & 0.232 & $(0.031)^{*}$ \\
\hline $\ln \left(y_{i t}^{U S A} / y_{i t}\right)$ & 3.059 & $(1.654)^{* *}$ & 2.196 & $(1.185)^{* *}$ & 3.168 & $(1.589)^{*}$ \\
\hline $\ln \left(1+\pi_{i t}\right)$ & -0.774 & $(0.132)^{*}$ & -0.427 & $(0.123)^{*}$ & -0.060 & $(0.218)$ \\
\hline Constant & -1.717 & $(0.837)^{*}$ & -1.180 & $(0.896)^{\text {***: }}$ & *-2.668 & $(1.786)^{* * *}$ \\
\hline $\bar{R}^{2}$ & $47 \%$ & & $48 \%$ & & $43 \%$ & \\
\hline$F$-test & $9.254^{*}$ & & $8.598^{*}$ & & $4.775^{*}$ & \\
\hline$N T$ & 932 & & 1,253 & & 528 & \\
\hline Hausman & $3.813^{*}$ & & $6.176^{*}$ & & $5.162^{*}$ & \\
\hline \multicolumn{7}{|c|}{ Specification B: IV Within Estimation; $g\left(\pi_{i t}\right)=\ln \left(1+\pi_{i t}\right)$} \\
\hline $\ln \left(I_{i t} / y_{i t}\right)$ & 2.255 & $(0.487)^{*}$ & 2.765 & $(0.428)^{*}$ & 3.289 & $(0.607)^{*}$ \\
\hline $\ln \left(y_{i t}^{U S A} / y_{i t}\right)$ & -5.190 & $(1.541)^{*}$ & -3.939 & $(1.146)^{*}$ & -2.010 & $(1.585)^{* * *}$ \\
\hline $\ln \left(1+\pi_{i t}\right)$ & -0.922 & $(0.168)^{*}$ & -0.617 & $(0.147)^{*}$ & -0.448 & $(0.236)^{* *}$ \\
\hline Constant & 2.120 & $(0.944)^{*}$ & 1.720 & $(0.897)^{* *}$ & 1.287 & $(1.435)$ \\
\hline$\overline{\bar{R}}^{2}$ & $44 \%$ & & $46 \%$ & & $46 \%$ & \\
\hline$N T$ & 835 & & 1,086 & & 458 & \\
\hline \multicolumn{7}{|c|}{ Specification C: Within Estimation of the Spline Function; $g\left(\pi_{i t}\right)=\sum_{j=1}^{3} D_{j} \beta_{j} \log \left(1+\pi_{i t}\right)$} \\
\hline $\ln \left(I_{i t} / y_{i t}\right)$ & 0.258 & $(0.026)^{*}$ & 0.213 & $(0.020)^{*}$ & 0.219 & $(0.031)^{*}$ \\
\hline $\ln \left(y_{i t}^{U S A} / y_{i t}\right)$ & 3.635 & $(1.674)^{*}$ & 2.532 & $(1.190)^{*}$ & 3.347 & $(1.590)^{*}$ \\
\hline $\begin{array}{l}\pi_{i t} \\
\left(\ln \left[1+\pi_{i t}\right]-\ln [10]\right)\end{array}$ & -0.567 & $(0.164)^{*}$ & -0.182 & $(0.155)$ & 0.222 & $(0.272)$ \\
\hline $\begin{array}{r}\times 1\left(\pi_{i t}>10\right) \\
\left(\ln \left[1+\pi_{i t}\right]-\ln [20]\right)\end{array}$ & -1.053 & $(0.565)^{* *}$ & -1.117 & $(0.544)^{*}$ & -0.912 & $(0.971)$ \\
\hline$\times 1\left(\pi_{i t}>20\right)$ & 0.589 & (1.153) & 0.297 & (1.039) & -0.849 & (1.767) \\
\hline Constant & -2.037 & $(0.849)^{*}$ & -1.431 & $(0.901)^{* *}$ & * -2.827 & $(1.789)^{* * *}$ \\
\hline$\overline{\bar{R}}^{2}$ & $47 \%$ & & $48 \%$ & & $43 \%$ & \\
\hline$F$-test & $9.024^{*}$ & & $8.588^{*}$ & & $4.856^{*}$ & \\
\hline$N T$ & 932 & & 1,253 & & 528 & \\
\hline
\end{tabular}

Notes: ${ }^{\#} p$-value of $F$-test for joint significance of all of the unobserved (fixed) effects (null model, are jointly zero); Hausman is the Hausman test for endogeneity of the inflation variable (null model is of exogeneity); robust standard errors in parentheses; * reject (two-sided) null hypothesis at 5\% size; ${ }^{* *}$ reject (two-sided) null hypothesis at $10 \%$ size; ${ }^{* * *}$ reject (one-sided) null hypothesis at $10 \%$ size. 
Table 3: Quadratic in Inflation, Quadratic in Inflation IVs and Spline Function in Levels

\begin{tabular}{|c|c|c|c|c|c|c|}
\hline & \multicolumn{2}{|c|}{$\begin{array}{c}\text { OECD } \\
\text { Coefficient }\end{array}$} & $\begin{array}{c}\text { FULL } \\
\text { Coefficien } \\
\end{array}$ & \multicolumn{3}{|c|}{$\begin{array}{c}\text { APEC } \\
\text { Coefficient } \\
\end{array}$} \\
\hline \multicolumn{7}{|c|}{ Specification A: Within Estimation of the Quadratic Function; $g\left(\pi_{i t}\right)=\sum_{j=1}^{2} \beta_{j} \pi_{i t}^{j}$} \\
\hline $\ln \left(I_{i t} / y_{i t}\right)$ & 0.263 & $(0.026)^{*}$ & 0.220 & $(0.020)^{*}$ & 0.231 & $(0.031)^{*}$ \\
\hline $\ln \left(y_{i t}^{U S A} / y_{i t}\right)$ & 4.024 & $(1.652)^{*}$ & 2.375 & $(1.203)^{*}$ & 3.379 & $(1.614)^{*}$ \\
\hline$\pi_{i t}$ & -0.196 & $(0.032)^{*}$ & -0.075 & $(0.029)^{*}$ & 0.059 & $(0.051)$ \\
\hline$\pi_{i t}^{2}$ & 0.003 & $(0.001)^{*}$ & 0.001 & $(0.001)^{*}$ & -0.002 & $(0.001)^{* *}$ \\
\hline Constant & -2.233 & $(0.823)^{*}$ & -1.545 & $(0.907)$ & -3.167 & $(1.810)^{* *}$ \\
\hline$\overline{\bar{R}}^{2}$ & $48 \%$ & & $46 \%$ & & $41 \%$ & \\
\hline$F$-test & $9.264^{*}$ & & $8.332^{*}$ & & $4.879^{*}$ & \\
\hline$N T$ & 937 & & 1,277 & & 549 & \\
\hline Hausman & $2.496^{*}$ & & $5.211^{*}$ & & $5.143^{*}$ & \\
\hline \multicolumn{7}{|c|}{ Specification B: IV Within Estimation of the Quadratic Function; $g\left(\pi_{i t}\right)=\sum_{j=1}^{2} \beta_{j} \pi_{i t}^{j}$} \\
\hline $\ln \left(I_{i t} / y_{i t}\right)$ & 0.323 & $(0.102)^{*}$ & 0.500 & $(0.080)^{*}$ & 0.704 & $(0.114)^{*}$ \\
\hline $\ln \left(y_{i t}^{U S A} / y_{i t}\right)$ & -0.004 & $(0.003)$ & -0.008 & $(0.002)^{*}$ & -0.010 & $(0.003)^{*}$ \\
\hline$\pi_{i t}$ & -0.206 & $(0.038)^{*}$ & -0.086 & $(0.033)^{*}$ & -0.020 & $(0.050)$ \\
\hline$\pi_{i t}^{2}$ & 0.003 & $(0.001)^{*}$ & 0.000 & $(0.001)$ & -0.002 & $(0.001)^{* *}$ \\
\hline Constant & 2.800 & $(0.591)^{*}$ & 1.647 & $(0.476)^{*}$ & 1.073 & $(0.666)$ \\
\hline$\overline{\bar{R}^{2}}$ & $44 \%$ & & $46 \%$ & & $48 \%$ & \\
\hline$N T$ & 837 & & 1,102 & & 474 & \\
\hline \multicolumn{7}{|c|}{ Specification C: Within Estimation of the Spline Function; $g\left(\pi_{i t}\right)=\sum_{j=1}^{3} D_{j} \beta_{j} \pi_{i t}$} \\
\hline $\ln \left(I_{i t} / y_{i t}\right)$ & 0.264 & $(0.026)^{*}$ & 0.217 & $(0.020)^{*}$ & 0.231 & $(0.031)^{*}$ \\
\hline $\ln \left(y_{i t}^{U S A} / y_{i t}\right)$ & 3.896 & $(1.653)^{*}$ & 2.505 & $(1.208)^{*}$ & 3.467 & $(1.624)^{*}$ \\
\hline$\pi_{i t}$ & -0.186 & $(0.036)^{*}$ & -0.044 & $(0.034)^{* * *}$ & 0.060 & $(0.056)$ \\
\hline$\left(\pi_{i t}-10\right) \times 1\left(\pi_{i t}>10\right)$ & 0.095 & $(0.063)^{* * * *}$ & -0.058 & $(0.061)$ & -0.112 & $(0.106)$ \\
\hline$\left(\pi_{i t}-20\right) \times 1\left(\pi_{i t}>20\right)$ & 0.066 & $(0.059)^{* * *}$ & 0.080 & $(0.057)^{* * *}$ & -0.005 & $(0.103)$ \\
\hline Constant & -2.207 & $(0.826)^{*}$ & -1.646 & $(0.911)^{* *}$ & -3.273 & $(1.823)^{* *}$ \\
\hline$\overline{\bar{R}^{2}}$ & $48 \%$ & & $46 \%$ & & $41 \%$ & \\
\hline$F$-test & $9.165^{*}$ & & $8.280^{*}$ & & $4.856^{*}$ & \\
\hline$N T$ & 937 & & 1,277 & & 549 & \\
\hline
\end{tabular}

Notes: " ${ }^{\text {see notes to Table } 2 .}$ 
Figure 5: Log Specification

Inflation-Growth Relationship, OECD, Inflation $<50 \%$

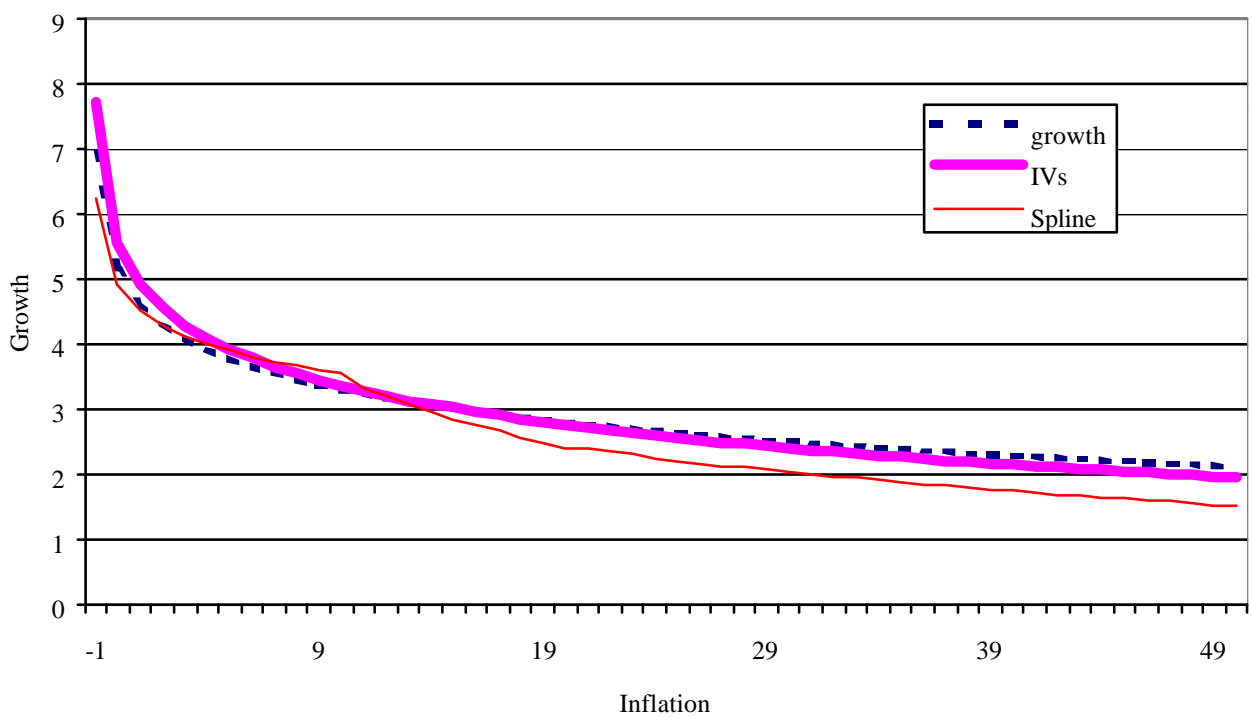

Figure 6: Quadratic Specification

Inflation-Growth Relationship, OECD, Inflation $<50 \%$

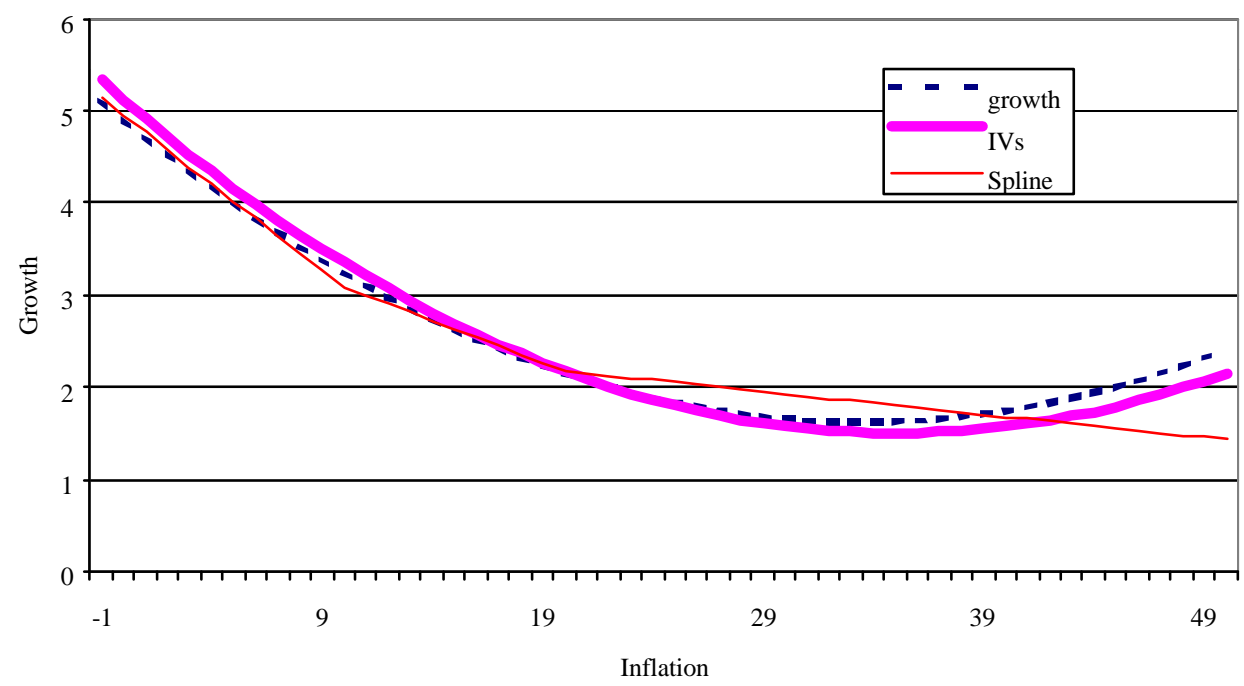


Figure 7: Log Specification

Inflation-Growth Relationship, Full Sample, Inflation $<50 \%$

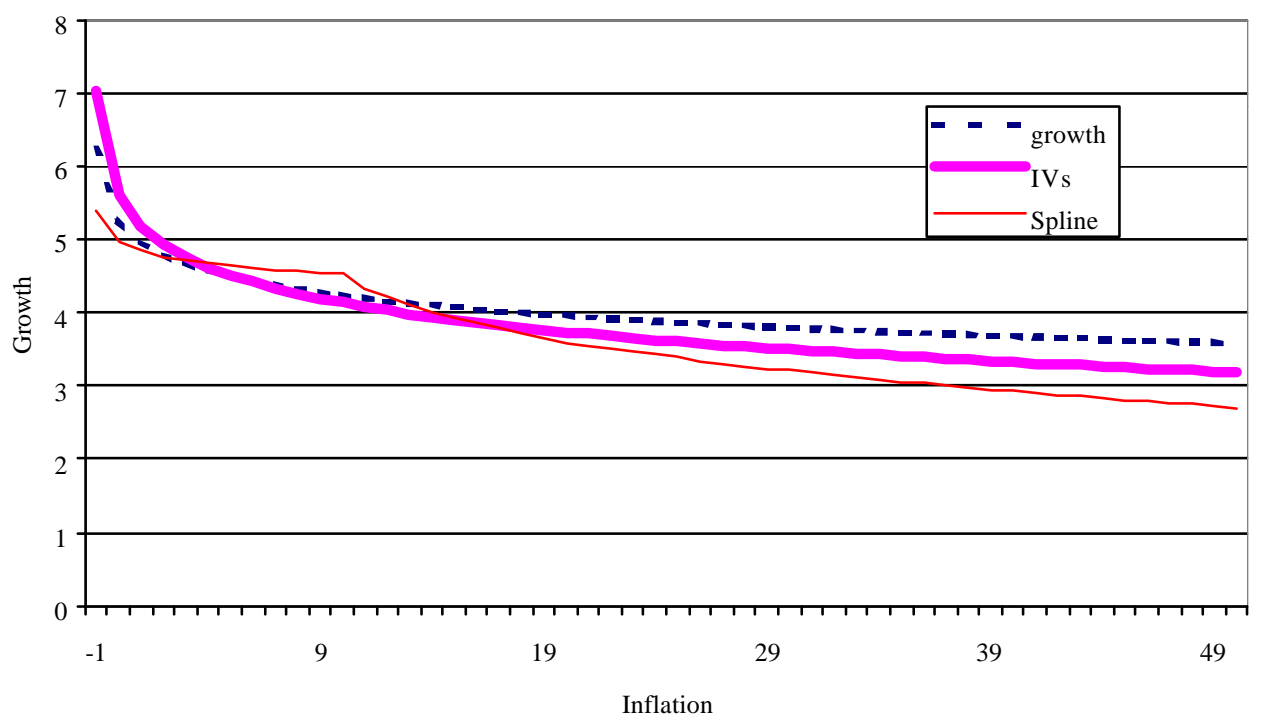

Figure 8: Quadratic Specification

Inflation-Growth Relationship, Full Sample, Inflation $<50 \%$

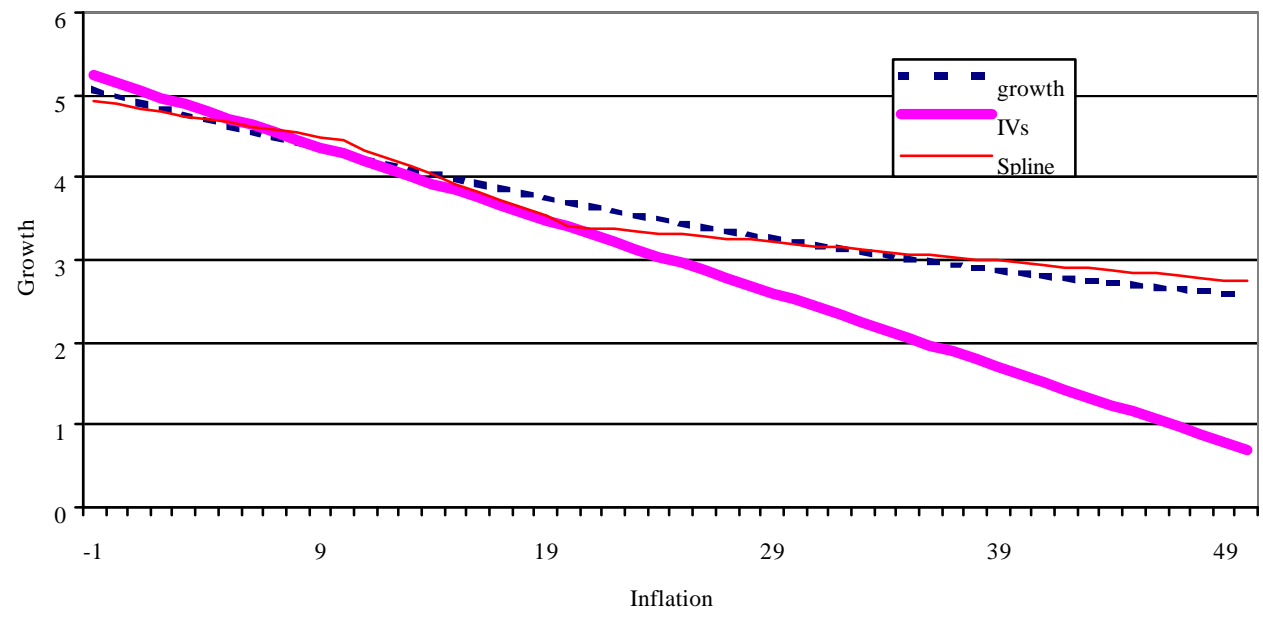


Figure 9: Log Specification

Inflation-Growth Relationship, APEC, Inflation $<50 \%$

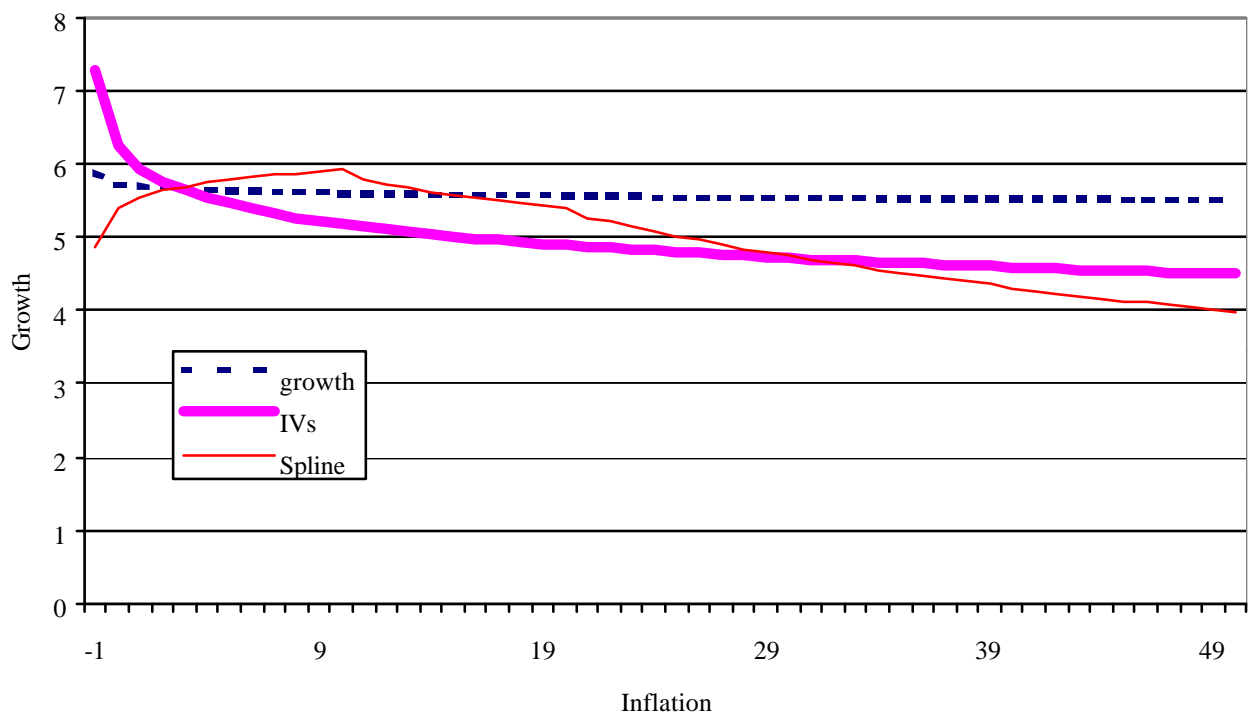

Figure 10: Quadratic Specification

Inflation-Growth Relationship, APEC, Inflation $<50 \%$

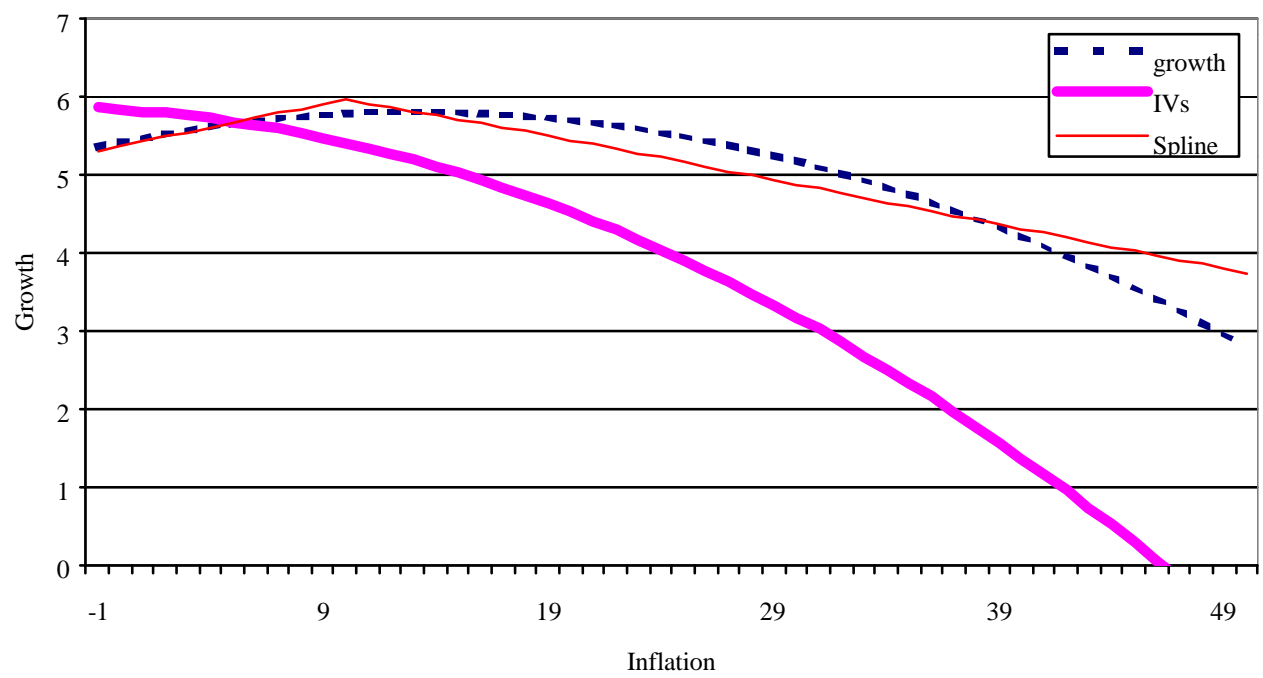

